\title{
Sonographic and histopathological correlation and evaluation of causes of abnormal uterine bleeding in perimenopausal women
}

\author{
Garima Kumari ${ }^{1 *}$, Kuldeep Poonia ${ }^{2}$
}

\begin{abstract}
${ }^{1}$ Department of Obstetrics and Gynecology, SMS Medical College and Hospital, Jaipur, Rajasthan, India
${ }^{2}$ Department of Surgery, SMS Medical College and Hospital, Jaipur, Rajasthan, India
\end{abstract}

Received: 18 June 2019

Revised: 09 September 2019

Accepted: 13 September 2019

\author{
*Correspondence: \\ Dr. Garima Kumari, \\ E-mail: garimabagaria22@gmail.com
}

Copyright: () the author(s), publisher and licensee Medip Academy. This is an open-access article distributed under the terms of the Creative Commons Attribution Non-Commercial License, which permits unrestricted non-commercial use, distribution, and reproduction in any medium, provided the original work is properly cited.

\section{ABSTRACT}

Background: Perimenopausal period in a woman's lifetime marks a transition from reproductive phase to that of menopause. Abnormal uterine bleeding (AUB) is a common problem among women in the reproductive age.

Methods: It was a prospective study on 100 perimenopausal women in age group 39-51 years with abnormal uterine bleeding who underwent Hysterectomy at SMS Hospital, Jaipur. At the end clinical diagnosis, ultrasonographic findings and histopathological reports were correlated.

Results: $42.0 \%$ cases had HMB menstrual pattern followed by $24.0 \%$ cases had HPMB and $18.0 \%$ of the cases had PB. Intermenstrual bleeding was seen in $2 \%$ cases. In clinical finding, $71.0 \%$ cases had fibroid followed by $15.0 \%$ cases had adenomyosis and $6.0 \%$ of the cases had fibroid+adenomyosis. The clinical diagnosis was confirmed by ultrasonography. Ultrasound detected fibroid in $95.8 \%$ of the cases who were suspected to have fibroid on clinical examination. Out of the 15 patients who were clinically suspected to have adenomyosis, 53.3\% confirmed on ultrasound, ultimate diagnosis was made on the basis of histology, so every hysterectomy specimen was sent for histopathological examination. Out of the 68 patients who were diagnosed to have fibroid uterus on ultrsonography, 66 patients were confirmed to have fibroid. Out of the 8 patients who were labelled as adenomyosis after ultrasound, 4 patients were diagnosed to have adenomyosis on histopathology and in rest 4 patients, no gross pathology was detected.

Conclusions: A transvaginal ultrasound should be offered as the first line of imaging. Clinical, radiological and pathological evaluation correlated well to diagnose fibroids, however clinically as well as USG proved to be of little help in diagnosing adenomyosis.

Keywords: Adenomyosis, Fibroid, Hysterectomy, Perimenopause

\section{INTRODUCTION}

WHO has defined perimenopause as period immediate prior to menopause when the endocrinological, biological and clinical features of approaching menopause commence and the first year after menopause. ${ }^{1-2}$ Menopausal transition (MT) develops during the first phase of menopause, the hyperhormonal one, by a marked increase of estrogen, in fact by accumulation (relative hyperestrogenia), with progesterone being absent. Aluteal cycles occur, the major cause of bleeding in the menopause transition. During this period, follicles become more resistant to gonadotrophin stimulation, despite normal levels of estrogen and the presence of 
monthly menstruation, which suffers a multitude of changes. The pattern of the changes in the menstrual cycle is the single most important clinical change in MT as it is immediately observed by that woman and moreover, the pattern analysis may indicate future changes. Anovulatory cycles become more frequent with completing the transition. Menstrual disorders are a common indication for medical visits among women of reproductive age and heavy menstrual bleeding affects up to $30 \%$ of women throughout their reproductive lifetime..$^{3,4}$ These complaints may significantly affect quality of life result in time off work lead to surgical intervention including hysterectomy and ultimately have significant impact on the health care system..$^{5-8}$

Management of such common condition in a population with wide healthcare diversity requires uniform clinical practice guidelines. As a consequence, abnormal uterine bleeding (AUB) is a common complaint in this age group accounting for $33 \%$ of patients attending gynecologic

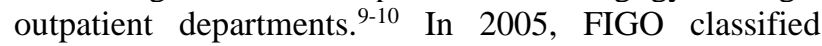
structural and nonstructural causes of abnormal uterine bleeding into PALM COEIN11-12: P- Polyp, AAdenomyosis, L-Leiomyoma, M- Malignancy, Hhyperplasia, C-Coagulation disorders, O- Ovulatory dysfunction, E-Endometrial local causes, I-Iatrogenic, NNot yet classified reserved for causes yet to be classified.

This imminent need for prompt diagnosis lead to a search for a diagnostic method that is simple, affordable, acceptable and accurate. Transvaginal ultrasound is a simple, minimally invasive method for studying the endometrium and detecting organic pathology responsible for abnormal uterine bleeding. This is often the first step in evaluation of AUB. Histopathology is the gold standard in diagnosing causes for AUB. The present study aims to correlate clinical and sonographical findings with histopathology findings. Uterine bleeding in perimenopausal age group stems from the fact that it may be the only clinical sign of an underlying hyperplasia or malignancy. With the marked increase in obesity, diabetes mellitus and metabolic syndrome- all known risk factors for Importance of abnormal endometrial carcinoma, the incidence of endometrial carcinoma is increasing.

\section{METHODS}

This study was conducted in the department of obstetrics and gynecology and surgery SMS Hospital, Jaipur, Rajasthan. All patients attending gynaecolgy OPD at SMS hospital with abnormal uterine bleeding. It was a prospective study. A total 100 patients were recruited from April 2016 till May 2018.

\section{Calculation of sample size}

The following formula will be applied for calculation of the sample size $n=4 p q / L^{2}$
Where,

$\mathrm{n}=$ sample size

$\mathrm{p}=$ positive character $\mathrm{q}=1-\mathrm{p}$

$\mathrm{L}=$ Allowable error

As Incidence is $50 \%$, hence $\mathrm{p}=0.5 \mathrm{q}=0.5$

$\mathrm{L}=10 \%=0.1$

$\mathrm{n}=4 \times 0.5 \times 0.5 / 0.1 \times 0.1=100$

Thus by applying this formula minimal sample size required is 100 .

\section{Inclusion criteria}

- Patients complaining of abnormal uterine bleeding Age 39 to 51 years

- Married and unmarried Nulliparous and multiparous.

\section{Exclusion criteria}

- All systemic causes of abnormal uterine bleeding.

It was a prospective study on 100 perimenopausal women in age group 39-51 years with abnormal uterine bleeding who underwent Hysterectomy at SMS Hospital.

Informed consent taken from every patient included in the study after giving them a copy of patient information sheet that explains the purpose and nature of study. Detailed history and clinical evaluation findings were noted as per the study proforma.

Clinical diagnosis was made on the basis of presenting complaint and clinical examination including per vaginum examination.

All these patients were subjected to routine investigations like haemoglobin percentage, blood counts, blood sugar level, urine examination (routine and microscopy), bleeding time, clotting time to rule out any other pathology and as a part of pre anaesthetic check up.

Ultrasound of pelvis did in all cases to look for organic causes of menstrual dysfunction. In patients with an obvious structural pathology responsible for abnormal bleeding and patients with recurrent complaints, direct hysterectomy was resorted to as a part of management.

Histopathology sample of the hysterectomy specimens were analyzed.

At the end clinical diagnosis, ultrasonographic findings and histopathological reports were correlated.

\section{The following were analysed}

- Distribution according to menstrual complaints

- Size of uterus

- Clinical findings

- Ultrasound diagnosis 
- Histopathology reports of hysterectomy specimen.

\section{Data collection}

According to the proforma approved by the guide and co -guide which included all the details of clinical and diagnostic tests done.

\section{Data entry}

Data was entered on Microsoft excel for the convenience of transport to analysis software.

\section{Statistical analysis}

In this study all the analysis will be performed by using statistical software SPSS Version 10.0.

\section{Descriptive analysis}

In this study, all continuous variables will be summarized by (number of observations, mean and standard deviation). Categorical values will be summarized by using frequencies and percentages between menstrual pattern with age group of study cases and parity were estimated by Chi Square test. Association between age group and parity were also assessed by chi square test.

\section{RESULTS}

In this study there were 100 cases that satisfied the inclusion and exclusion criteria and underwent hysterectomy.
Table 1: Profile of menstrual pattern among the cases.

\begin{tabular}{|lll|}
\hline Menstrual pattern & $\begin{array}{l}\text { No. of cases } \\
(\mathbf{N}=100)\end{array}$ & Percentage \\
\hline FMB & 12 & 12.0 \\
\hline HMB & 42 & 42.0 \\
\hline HPMB & 24 & 24.0 \\
\hline IMSP & 04 & 04.0 \\
\hline PB & 18 & 18.0 \\
\hline
\end{tabular}

Above table reveals that, $42.0 \%$ cases had HMB Menstrual pattern followed by $24.0 \%$ cases had HPMB and $18.0 \%$ of the cases had PB. Heavy menstrual bleeding was the most common complaint followed by heavy prolonged menstrual bleeding, prolonged bleeding and frequent menstrual bleeding respectively. Frequent bleeding included frequent heavy and frequent prolonged menstrual bleeding. Intermenstrual bleeding was seen in $2 \%$ cases.

In our study of 100 cases maximum numbers of cases were with uterine size less than 12 weeks that is 52 , next with uterine size $12-16$ weeks were 36 cases. Only 12 cases were seen with uterine size more than 16 weeks.

Table 2: Profile of uterus size among the cases.

\begin{tabular}{|lll|}
\hline Uterus size (weeks) & $\begin{array}{l}\text { No. of cases } \\
(\mathbf{N}=100)\end{array}$ & Percentage \\
\hline$<12$ & 52 & 52.0 \\
\hline $12-16$ & 36 & 36.0 \\
\hline$>16$ & 12 & 12.0 \\
\hline
\end{tabular}

Table 3: Association between age group and menstrual pattern.

\begin{tabular}{|lllllll|}
\hline $\begin{array}{l}\text { Age group } \\
\text { (years) }\end{array}$ & N & FMB No. (\%) & HMB No. (\%) & HPMB No. (\%) & IMSP No. (\%) & PB No. (\%) \\
\hline $39-43$ & 19 & - & $09(47.4)$ & $07(36.8)$ & - & $03(15.8)$ \\
\hline $44-47$ & 41 & $06(14.6)$ & $18(43.9)$ & $10(24.4)$ & - & $07(17.1)$ \\
\hline $48-51$ & 40 & $06(15.0)$ & $15(37.5)$ & $07(17.5)$ & $04(10.0)$ & $08(20.0)$ \\
\hline
\end{tabular}

By Chi Square test; $\mathrm{P}>0.05$, Not Significant.

Table 4: Association between age group and histopathology report.

\begin{tabular}{|lllllll|}
\hline $\begin{array}{l}\text { Age groups } \\
\text { (years) }\end{array}$ & $\begin{array}{l}\text { Adenomyos } \\
\text { is No. }(\%)\end{array}$ & $\begin{array}{l}\text { Fibroid } \\
\text { No. }(\%)\end{array}$ & $\begin{array}{l}\text { Fibroid+adenomyosis } \\
\text { No. }(\%)\end{array}$ & $\begin{array}{l}\text { Endometrial } \\
\text { hyperplasia No. (\%) }\end{array}$ & $\begin{array}{l}\text { Fibroid Polyp } \\
\text { No. (\%) }\end{array}$ & $\begin{array}{l}\text { Normal } \\
\text { No. }(\%)\end{array}$ \\
\hline $39-43(\mathrm{~N}=19)$ & - & $12(63.1)$ & $01(05.3)$ & $02(10.5)$ & - & $04(21.1)$ \\
\hline $44-47(\mathrm{~N}=41)$ & $01(02.4)$ & $30(73.2)$ & $02(04.9)$ & $01(02.4)$ & - & $07(17.1)$ \\
\hline $48-51(\mathrm{~N}=40)$ & $03(07.5)$ & $24(60.0)$ & - & $02(05.0)$ & $02(05.0)$ & $09(22.5)$ \\
\hline
\end{tabular}

By Chi Square test; $\mathrm{P}>0.05$, Not Significant.

Above table reveals that, $47.4 \%$ of the cases who belongs to age group 39-43years had HMB which Was more as compared to $37.5 \%$ of the cases who belongs to 48 51years but the difference was not significant.
$63.1 \%$ of the cases who belongs to age group 39-43years had fibroid which was less as compared to $73.2 \%$ of the cases who belongs to 44-47years but the difference was not significant. 
In this Table 5, 53.1\% of the cases with fibroid had HMB menstrual pattern which was more as compared to $20.0 \%$ of the cases who had endometrial hyperplasia but the difference was not significant.
In Table 6 reveals that, in clinical finding, $71.0 \%$ cases had Fibroid followed by $15.0 \%$ cases had adenomyosis and $6.0 \%$ of the cases had fibroid + adenomyosis. The clinical diagnosis was confirmed by ultrasonography.

Table 5: Association between histopathology reports and menstrual pattern.

\begin{tabular}{|lllllll|}
\hline Histopathology report & N & $\begin{array}{l}\text { FMB No. } \\
(\boldsymbol{\%})\end{array}$ & $\begin{array}{l}\text { HMB No. } \\
(\boldsymbol{\%})\end{array}$ & $\begin{array}{l}\text { HPMB No. } \\
(\boldsymbol{\%})\end{array}$ & $\begin{array}{l}\text { IMSP No. } \\
(\boldsymbol{\%})\end{array}$ & $\begin{array}{l}\text { PB No. } \\
(\boldsymbol{\%})\end{array}$ \\
\hline Adenomyosis & 04 & $01(25.0)$ & - & $01(25.0)$ & - & $02(50.0)$ \\
\hline Fibroid & 66 & $07(10.6)$ & $35(53.1)$ & $15(22.7)$ & $01(01.5)$ & $08(12.1)$ \\
\hline Fibroid + adenomyosis & 03 & $01(33.3)$ & - & $01(33.3)$ & - & $01(33.4)$ \\
\hline Endometrial hyperplasia & 05 & - & $01(20.0)$ & $04(80.0)$ & - & - \\
\hline Fibroid + Polyp & 02 & - & - & - & $02(100.0)$ & - \\
\hline Normal & 20 & $03(15.0)$ & $06(30.0)$ & $03(15.0)$ & $01(05.0)$ & $07(35.0)$ \\
\hline
\end{tabular}

By Chi Square test; $\mathrm{P}>0.05$, Not Significant.

Table 6: Comparison of clinical, usg and histopathology diagnosis of patients that underwent hysterectomy.

\begin{tabular}{|llll|}
\hline Pathology & $\begin{array}{l}\text { Clinical findings } \\
(\mathbf{N}=\mathbf{1 0 0})\end{array}$ & $\begin{array}{l}\text { Ultrasonography impression } \\
(\mathbf{N}=\mathbf{1 0 0})\end{array}$ & $\begin{array}{l}\text { Histopathology report } \\
\mathbf{N}=\mathbf{1 0 0})\end{array}$ \\
\hline No. $(\mathbf{\%})$ & $\mathbf{N o}(\mathbf{\%})$ & $\mathbf{N o}(\mathbf{\%})$ \\
\hline Adenomyosis & $15(15.0)$ & $08(08.0)$ & $04(04.0)$ \\
\hline Fibroid & $71(71.0)$ & $68(68.0)$ & $66(66.0)$ \\
\hline Fibroid + Adenomyosis & $06(06.0)$ & $06(06.0)$ & $03(03.0)$ \\
\hline Endometrial hyperplasia & - & $03(03.0)$ & $05(05.0)$ \\
\hline Fibroid Polyp & $03(03.0)$ & $02(02.0)$ & $02(02.0)$ \\
\hline No gross pathology & $05(05.0)$ & $13(13.0)$ & $20(20.0)$ \\
\hline
\end{tabular}

Ultrasound detected fibroid in $95.8 \%$ of the cases who were suspected to have fibroid on clinical examination. Out of the 15 patients who were clinically suspected to have adenomyosis, $53.3 \%$ confirmed on ultrasound. Ultimate diagnosis was made on the basis of histology, so every hysterectomy specimen was sent for histopathological examination. Out of the 68 patients who were diagnosed to have fibroid uterus on ultrsonography, 66 patients were confirmed to have fibroid. Out of the 8 patients who were labelled as adenomyosis after ultrasound, 4 patients were diagnosed to have adenomyosis on histopathology and in rest 4 patients, no gross pathology was detected.

\section{DISCUSSION}

This is a prospective study of 100 patients of perimenopausal age group (from 39-51years) with abnormal uterine bleeding, attending gynaecology outpatient department of SMS Hospital, Jaipur.

\section{Menstrual pattern wise distribution}

In our study, heavy menstrual bleeding (42\%) was the most common complaint followed by heavy prolonged bleeding $(24 \%)$. Considering that heavy menstrual bleeding, heavy prolonged bleeding and prolonged bleeding came under the older terminology 'menorrhagia', frequent menstrual bleeding under polymenorrhea in the older terminology. A comparison with other studies is given in the table that follows. Heavy menstrual bleeding was the most common menstrual complaint in all the studies. But they differed in the reporting of next common menstrual symptoms. The menstrual pattern of present study is compared with following study.

Table 7: Menstrual pattern of present study is compared with following study.

\begin{tabular}{|c|c|c|}
\hline Authors & Menorrhagia & Polymenorrhea \\
\hline Gupta A et al ${ }^{13}$ & $72 \%$ & $7 \%$ \\
\hline Bhosle $\mathrm{A}$ et $\mathrm{al}^{14}$ & $53.3 \%$ & $28.2 \%$ \\
\hline Mahapatra $\mathrm{M}^{15}$ & $48.6 \%$ & $10 \%$ \\
\hline Verma $\mathrm{R}^{16}$ & $40 \%$ & $14 \%$ \\
\hline Present study & $42 \%$ & $12 \%$ \\
\hline
\end{tabular}

\section{Distribution of pathology in hysterectomy specimens}

Leiomyoma is the most common finding (66\%) on histopathology followed by cases having endometrial hyperplasia $(5 \%)$, adenomyosis alone $(4 \%)$, fibroid plus adenomyosis $(3 \%)$ and polyp $(2 \%)$ respectively. There were 20 cases in which no gross pathology was detected on histopathology. Fibroids were the most common 
findings in studies by Gupta et al, and Archana Bhosle and Michelle Fonsesca. ${ }^{13,14}$ While adenomyosis was the second common finding in the latter study, DUB (AUBovulatory/endometrial) was the second common finding in the former. In almost all studies mentioned above shows most common histopathological finding as Fibroid which is comparable to our study except Rizvi et al and Mehta $\mathrm{S}$ et al studies which shows Adenomyosis as common pathology.

\section{Clinical, ultrasonographic and histopathological correlation}

In our study, clinical, radiological and pathological evaluation correlated well to diagnose fibroids, however clinically as well as USG proved to be of little help in diagnosing adenomyosis, which is similar with studies by Gupta et al and Bhosle A and Michelle Fonseca. ${ }^{13,14}$ In Gupta et al, out of 100 cases, 63 cases who were dignosed to have fibroid uterus on ultrasonography, 53 cases were confirmed to have leiomyoma on histopathology and 10 cases had adenomyosis as well as leiomyoma. The clinical diagnosis was confirmed by ultrasonography. Ultrasound detected fibroid in $100 \%$ of the cases who were suspected to have fibroid on clinical examination.

In Bhosle A and Michelle Fonseca study, out of 55 cases of fibroid uterus found on clinical examination, 53 cases confirmed on ultrasonography but final diagnosis was given by histopathology which showed fibroid uterus in 46 cases. Only 8 cases of adenomyosis were found clinically but on ultrasound 19 cases showed adenomyosis and 25 cases confirmed to have adenomyosis on histopathology. This shows very poor correlation of adenomyosis. ${ }^{14}$ In study by Neena $\mathrm{Y}$ and Honey B, there was a very high correlation when the clinical diagnosis was fibroid same as our study. ${ }^{17} \mathrm{~A}$ clinic-pathological correlation by Gupta $\mathrm{G}$ et al, showed that clinical and pathological correlation is $100 \%$ in cases of leiomyoma. ${ }^{18}$ Mehta $\mathrm{S}$ et al and Ramachandran $\mathrm{T}$ et al, similar results as our study. ${ }^{19}$

\section{CONCLUSION}

Heavy menstrual bleeding is the most common menstrual complaint, a transvaginal ultrasound should be offered as the first line of imaging as it is relatively cheap, minimally invasive and acceptable method to detect structural causes for bleeding and endometrial thickness, fibroid is the most common lesion on hysterectomy and endometrial hyperplasia the most common endometrial pathology, clinical, radiological and pathological evaluation correlated well to diagnose fibroids, however clinically as well as USG proved to be of little help in diagnosing adenomyosis, histopathological diagnosis varies in relation to menstrual complaints, age, associated symptoms and endometrial thickness. Hence, complete details have to be provided to the pathologist along with the samples.
Funding: No funding sources

Conflict of interest: None declared

Ethical approval: The study was approved by the Institutional Ethics Committee

\section{REFERENCES}

1. Burger HG, Dudley EC, Hopper JL. The endocrinology of the menopausal transition: A crosssectional study of a population-based sample. J Clin Endocrinol Metab. 1995;80:3537-45.

2. Prior JC. Perimenopause: The complex endocrinology of the menopausal transition. Endocr Rev. 1998;19:397-428.

3. Kjerulff KH, Erickson BA, Langenberg PW. Chronic gynecological conditions reported by US women: findings from the national health interview survey, 1984 to 1992. Am J Public Health. 1996;86:195-9.

4. Market Opinion and Research International (MORI). Women's health in 1990. Research study conducted on behalf of Parke-Davis Laboratories. London: MORI; 1990.

5. Barnard K, Frayne SM, Skinner KM, Sullivan LM. Health status among women with menstrual symptoms. J Womens Health (Larchmt). 2003;12:911-9.

6. Cote I, Jacobs P, Cumming D. Work loss associated with increased menstrual loss in the United States. Obstet Gynecol. 2002;100:683-7.

7. Millar W. Hysterectomy, $1981 / 82$ to $1996 / 97$. Health Rep. 2001;12:9-22.

8. Frick KD, Clark MA, Steinwachs DM, Langenberg P, Stovall D, Munro MG, et al. Financial and qualityof-life burden of dysfunctional uterine bleeding among women agreeing to obtain surgical treatment. Womens Health Issues. 2009;19:70-8.

9. Awwad JT, Toth TL, Schiff I. Abnormal uterine bleeding in the perimenopause. Int $\mathrm{J}$ Fertil Menopausal Stud. 1993;38(5):261-9.

10. Grimes DA. Diagnostic dilatation and curettage: a reappraisal. Am J Obstet Gynecol. 1982;42(1):1-6.

11. Munro M, Critchley HO, Fraser I. The FIGO classification of causes of abnormal uterine bleeding in the reproductive years. Fertil Steril. 2011;95(7):2204-8.

12. Malcolm GM, Hilary OD, Critchley, Michael SB, Ian SF. FIGO classification system (PALM- COEIN) for causes of abnormal uterine bleeding in nongravid women of reproductive age. Int J Gyn Obs. 2011;113(1):3-13.

13. Gupta A, Rathore AM, Manaktala U, Rudingwa P. Evaluation and histopathological correlation of abnormal uterine bleeding in perimenopausal women. IJBAR. 2013;04:509-13.

14. Archana B, Michelle F. Evaluation and histopathological correlation of abnormal uterine bleeding in perimenopausal women. J Bombay Hospital. 2010;52:69-72. 
15. Mahapatra M, Mishra P. Clinicopathological evaluation of abnormal uterine bleeding. J Health Res Rev. 2015;2:45-9.

16. Verma R. A study on abnormal uterine bleeding in perimenopausal age in rural Bihar. JMSCR. 2016;4(2):9262-74.

17. Yogesh N, Honey B. Clinico-pathological correlation of hysterectomy specimens for abnormal uterine bleeding in rural area. J Evol Med Dent Sci. 2013;2(39):7506-12.

18. Gupta G, Kotasthane D, Kotasthane V. Hysterectomy: a clinico-pathological correlation of 500 cases. The Int J Gynecol Obstet. 2009;14:1.
19. Thamilselvi, Sinha P. Correlation between clinicopathological and ultrasonographical findings in hysterectomy. J Clin Diagno Res. 2011;5(4):737-40.

Cite this article as: Kumari G, Poonia K.

Sonographic and histopathological correlation and evaluation of causes of abnormal uterine bleeding in perimenopausal women. Int J Reprod Contracept Obstet Gynecol 2019;8:3920-5. 